\title{
Intratubular Large Cell Hyalinizing Sertoli Cell Tumor of the Testes in Peutz-Jeghers Syndrome: A Case Report
}

\author{
Esra Polat ${ }^{1 *}$, Yasemin Özlük ${ }^{2}$ and Çağla Karaoğlan ${ }^{2}$ \\ ${ }^{1}$ Department of Pediatric Gastroenterology, Istanbul Sağlık Bilimleri University, Kanuni Sultan Süleyman \\ Educational and Research Hospital, Turkey \\ ${ }^{2}$ Department of Pathology, Istanbul Medical Faculty, Istanbul University, Turkey
}

*Corresponding author: Esra Polat, MD, Pediatrician, Pediatric Gastroenterologist, Department of Pediatric Gastroenterology, Istanbul Sağlık Bilimleri University Kanuni Sultan Süleyman Educational and Research Hospital, Elmalıkent M. Adem Yavuz C. No: 1, 34764, Umraniye/Istanbul, Turkey, Tel: 009005055500170, Fax: 00902166327124

\begin{abstract}
Background: Polyposis disorders of the bowel in the pediatric population are associated with elevated risks of various cancers. The most common sites of the malignancies were the gastrointestinal system, breast, gynecological organs, testis, pancreas and lung. Testicular lesions are often overlooked as PJS predominantly appear in females.

Case: A 9-year-old boy was presented to gastroenterology policlinic due to pallor. He had a history of diagnostic laparotomy when he was nine dues to acute abdomen where intussusception related to ileal hamartomatous polyp was diagnosed. He had bluish-black pigmentations on the lips and oral mucosa and bilateral gynecomastia. His testicular examination showed no masses. Thelarche and pubarche was tanner stage 2. Laboratory findings did not reveal any pathological result, except anemia (Serum hemoglobin level: $8.1 \mathrm{gr} / \mathrm{dl})$, low serum estradiol $(<5 \mathrm{pg} / \mathrm{mL}$; reference range: $25.8-60.7)$ and follicle-stimulating hormone (FSH) (0.58 $\mathrm{mlU} / \mathrm{mL}$; reference range: $1.5-12.4)$ levels. Multiple and different sized polyps were discovered on colonoscopy and esophago-gastroduodenoscopy. Histopathological investigation of the polyps was compatible with hamartoma. The mutation analysis of the testicular specimen later identified a heterozygote mutation of patient's STK11 genes (p.Gly 163Arg), on exon 4, consistent with the clinical diagnosis of PJS. The skeletal age (11 years) was older than the chronological age. Mammary ultrasounds proved bilateral gynecomasty and testicular ultrasonography showed bilateral multiple microcalcifications. The histopathological examination of testes wedge biopsies showed multifocal intratubular large cell hyalinizing tumors of Sertoli cells. The patient was referred to pediatric endocrinology department where aromatase inhibition therapy was initiated. After follow-up of one year, gynecomasty on the right disappeared while it was just minimal on the left breast.
\end{abstract}

Conclusions: First, any child who was diagnosed to have invagination should have been checked for familial polyposis syndromes. Second, any child with the suspicion of PJS should have routine mammary and testes ultrasounds. Any abnormality especially in testicles needs further evaluation including biopsy. Unexpected malignant pathologic appearance can be seen even in the youngers. Last, malignant Sertoli cell tumors of the testes can be followed up prescribing aromatase inhibitors without any need for orchiectomy.

\section{Keywords}

Peutz-jeghers syndrome, Children, Intratubular large cell hyalinizing sertoli cell tumor, Testicles

\begin{abstract}
Abbreviations
AMH: Anti-Müllerian Hormone; dl: Deciliters; GI: Gastrointestinal; gr: Grams; mL: Milliliters; mIU: Micro-International Unit; ng: Nanograms; LCCSCTs: Large cell calcifying sertoli cell tumors; PJS: Peutz-Jeghers syndrome; Pg: Pictograms
\end{abstract}

\section{Introduction}

Polyposis disorders of the bowel in the pediatric population require close medical care to minimize cancer risk in the gastrointestinal tract and in other organ systems [1]. Peutz-Jeghers syndrome (PJS), is a rare autosomal dominant disease manifests as multiple gastrointestinal hamartomatous polyposis, mucocutaneous pigmentation, and increased risk of gastrointestinal (GI) or extraintestinal neoplasia due to a germline mutation in the STK11(LKT1)/LKB1 gene located on the short arm of chromosome 19 [2]. The estimated lifetime cumulative cancer risk in individuals with PJS is over $76 \%$ in

Citation: Polat E, Özlük Y, Karaoğlan C (2018) Intratubular Large Cell Hyalinizing Sertoli Cell Tumor of the Testes in Peutz-Jeghers Syndrome: A Case Report. Int J Pathol Clin Res 4:080. doi.org/10.23937/2469$5807 / 1510080$

Accepted: November 10, 2018: Published: November 12, 2018

Copyright: (c) 2018 Polat E, et al. This is an open-access article distributed under the terms of the Creative Commons Attribution License, which permits unrestricted use, distribution, and reproduction in any medium, provided the original author and source are credited. 
Table 1: Initial laboratory results of the patient

\begin{tabular}{|l|l|l|}
\hline Laboratory measurement & Level and units & Reference range \\
\hline Hemoglobin & $8.1 \mathrm{gr} / \mathrm{dl}$ & $11-16$ \\
\hline Estradiol & $<5 \mathrm{pg} / \mathrm{mL}$ & $25.8-60.7$ \\
\hline Follicle-stimulating hormone & $0.58 \mathrm{mlU} / \mathrm{mL}$ & $1.5-12.4$ \\
\hline Luteinizing hormone & $0.326 \mathrm{mlU} / \mathrm{mL}$ & $0.1-1.4$ \\
\hline Beta-hCG & $<0.1 \mathrm{mlU} / \mathrm{mL}$ & $0-4$ in non-pregnants \\
\hline Anti-mullerian hormone & $53 \mathrm{ng} / \mathrm{mL}$ & $6.1-60.7$ \\
\hline TSH & $2.38 \mathrm{mlU} / \mathrm{mL}$ & $0.6-4.84$ \\
\hline Total testosterone & $0.28 \mathrm{ng} / \mathrm{mL}$ & $0.03-0.68$ \\
\hline AFP & $1.71 \mathrm{ng} / \mathrm{mL}$ & $<6.0$ in non-pregnants \\
\hline
\end{tabular}

Table 2: Characteristics of the polyps diagnosed in the gastrointestinal system of the boy.

\begin{tabular}{|l|l|}
\hline Number of polyps found & 15 \\
\hline Major size & $3 \mathrm{~cm}$ \\
\hline Locations & $\begin{array}{l}\text { lleum, rectum, antrum, bulbus, } \\
\text { duodenum }\left(2^{\text {nd }}, 3^{\text {rd }} \text { and } 4^{\text {th }} \text { parts }\right)\end{array}$ \\
\hline
\end{tabular}

comparison with the common population [2-4]. In other words, an 11-fold elevated risk of cancer has been reported in PJS [5]. The most common sites of the malignancies were the gastrointestinal system, especially colorectum, small intestine including the duodenum, and stomach; followed by the breast, gynecological organs (uterus, cervix and ovary), testis, pancreas, and lung [5,6]. Testicular lesions are often overlooked as PJS predominantly appear in females. Large cell calcifying sertoli cell tumors (LCCSCTS) have been associated with PJS. Most LCCSCTs have a benign clinical course, but malignancy rarely can occur especially in older ages. Malignancy is detected in about $17 \%$ of patients with LCCSCTs, usually occur at a mean age of 39 years while the mean age of presentation for benign tumors was 17 years [7].

Sometimes, unrecognized clues may aid to put further diagnosis in rare syndromes. Here, we report a boy who was proved to have Peutz-Jeghers syndrome (PJS) and multifocal intratubular large cell hyalinizing Sertoli cells neoplasia. This is one of the few cases that malignant course had been diagnosed in a relatively younger age.

\section{Case}

Informed consent forms were filled by the parents before enrollment. A 9-year-old white Turkish citizen boy was presented to gastroenterology policlinic in Istanbul due to pallor. He had a history of diagnostic laparotomy when he was nine due to acute abdomen where intussusception related to ileal hamartomatous polyp was diagnosed. His parents were distant kinships and his paternal grandfather had a history of bowel operation with an unknown cause. Physical examination revealed a height of $122 \mathrm{~cm}$ (3-10.p) and weight of 22 $\mathrm{kg}$ (3-10.p). He had bluish-black pigmentations on the lips and oral mucosa. He had bilateral gynecomastia. His testicular examination showed no masses. Thelarche and pubarche was tanner stage 2 . Laboratory findings

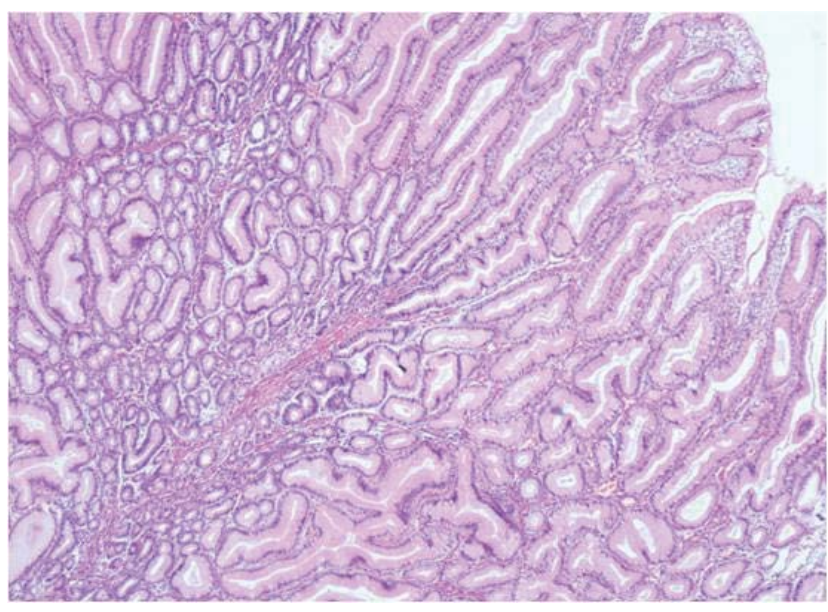

Figure 1: Polypectomy material showed features of hamartomatous polyp with characteristic arborizing smooth muscle pattern and hyperplastic epithelium (HE 40x).

are summarized in Table 1. Multiple and different sized polyps were discovered on colonoscopy and esophago-gastroduodenoscopy (Table 2). Polypectomy was performed, and histopathology was compatible with a hamartomatous polyp (Figure 1). The mutation analysis of the testicular specimen later identified a heterozygote mutation of patient's STK11 genes (p.Gly 163Arg), on exon 4, consistent with the clinical diagnosis of PJS.

The skeletal age (11 years) was older than the chronological age. Mammary ultrasounds proved bilateral gynecomasty and testicular ultrasonography showed bilateral multiple microcalcifications. The histopathological examination of testes wedge biopsies showed multifocal intratubular large cell hyalinizing tumors of Sertoli cells (Figure 2). The patient was referred to pediatric endocrinology department where aromatase inhibition therapy was initiated. After follow-up of one year, gynecomasty on the right disappeared while it was just minimal on the left breast.

\section{Discussion}

There is an age dependent symptom and complication range for patients with PJS: polyp-related complications may occur in childhood, whereas the gastrointestinal or genital cancer risks are predominantly associated with the adults [8]. Our case report is one of the few exceptions to this belief as he showed both polyps related and cancer related complications. Small intestine 


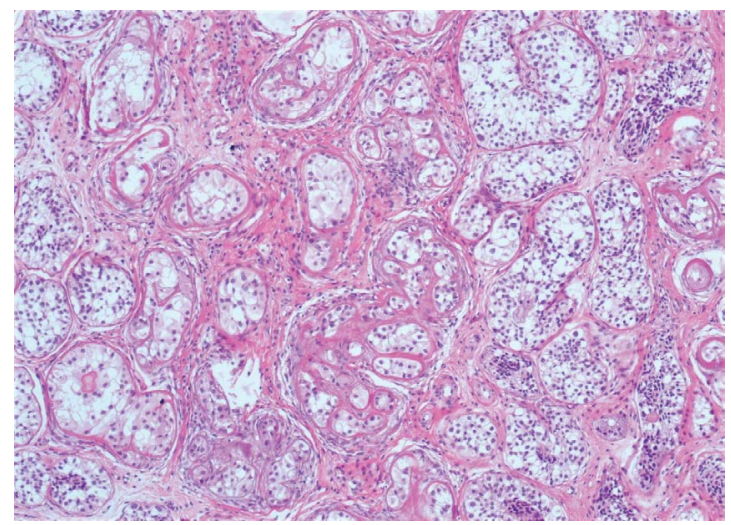

A

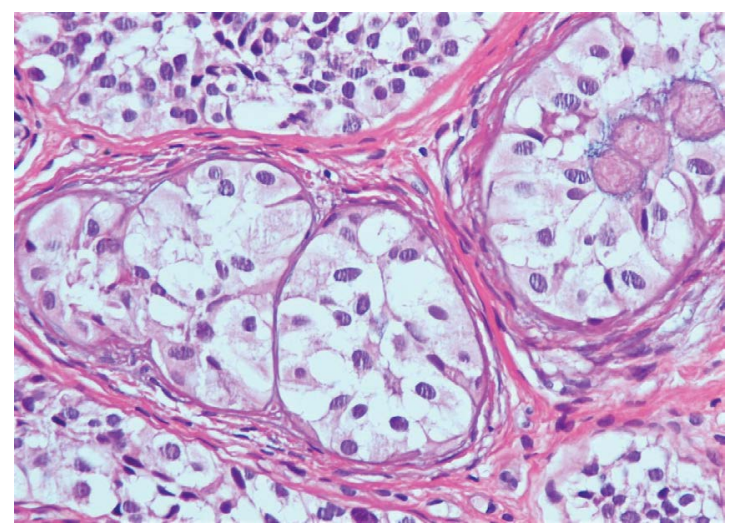

$\mathrm{C}$

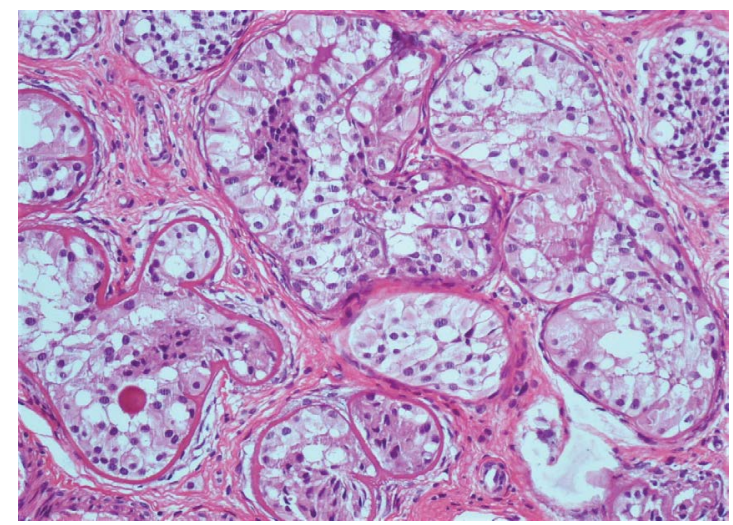

B

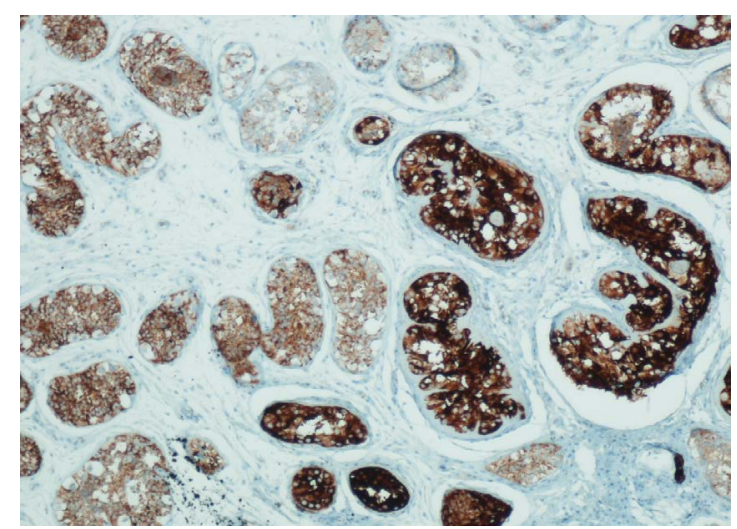

$\mathrm{D}$

Figure 2: A) Expanded seminiferous tubules that surrounded by prominent thickened basement membrane and fibrous bands (HE 100x); B,C) Neoplastic tubules were filled by large Sertoli cells with abundant eosinophilic cytoplasm and uniform and round-oval nuclei. Some affected tubules contain intratubular hyaline globules (HE 200x, 400x, respectively); D) Neoplastic and non-neoplastic Sertoli cells showed Inhibin positivity, but neoplastic Sertoli cells stain stronger than non-neoplastic Sertoli cells (anti-Inhibin antibody, 100x).

is the most typical localization of PJS polyps; also, coIon and stomach are generally involved [9]. The cardinal clinical hallmarks of PJS are anemia, rectal bleeding, obstruction, and/or intussusception [9]. Our patient also referred to our policlinic as a result of anemia associated symptoms such as pallor, weakness and fatigue. His history later revealed an operation possibly due to obstruction and/or intussusception related to polyposis.

The first case of feminizing Sertoli cell tumor in a child with PJS has been described in 1980 by Cantu, et al. [10]. Ulbright, et al. declared that the testicular tumors seen in PJS patients largely appears as multifocal intratubular large cell hyalinizing tumors of Sertoli cells with a noticeable morphology that varies from LCCSCTs and sex cord tumors with annular tubules. However, most authors nowadays except that syndrome associated testis tumors are LCCSCTs [3,11]. LCCSCTs occur with a frequency of 0.4-1.5\% among testicular neoplasias [3]. They are sporadic in $60 \%$ of the published cases, but in the remaining cases they are associated with multiple neoplasia syndromes such as PJS and Carney complex [7]. Mainly, the neoplasm resides within the borders of the tubules for several years [3]. Quite seldom it has been declared to progress to invasive large cell sertoli cell tumors with or without co-existing calcification as it is in our patient $[3,12]$. Invasive cancer risk is diminished in Sertoli cell tumors in young patients, in the existence of bilateral testicular involvement, and when they co-exist with genetic syndromes.

Sertoli cells are the structural cells of the testicles [7]. During the germinal maturation, Sertoli cells produce anti-Müllerian hormone (AMH) causing to degeneration of Müllerian ducts. Simultaneous testosterone stimulation of Leydig cells in fetus generates internal male genital organs [7]. Meantime the main duty of Sertoli cells is to induce the differentiation of spermatocytes [7]. Aromatase is the enzyme that converts testosterone to estradiol. This enzyme usually is not detected in testes before puberty and the level increases gradually thereafter. In normal situations, aromatase enzyme is produced mainly in Leydig cells; however, in testicular neoplasms that arise from Sertoli cells, these cells express aromatase $[7,13]$.

Ulbright, et al. [11] proved elevated levels of aromatase in Sertoli Cell Tumors with positive immunostains, which may confirm the estrogenic hyperactivity in PJS. High aromatase levels cause increased serum levels of estradiol and estrone using testosterone and androstenedione as substrates. Thus, prepubertal gyne- 
comastia becomes a typical initial presentation as it is in our patient. Hyperestrogenism cannot be caught in biochemical analyses, as the hormone production is restricted to testicular aromatase.

The physiopathologic basis of LCCSCTs in patients suffering PJS is not established yet. Possible blamed mechanisms include inhibition of AMP-activated protein kinase that triggers activation of mammalian target of rapamycin (mTOR) [7]. Others suggest that the gene abnormality of PJS may induce a cascade of effects causing overexpression of aromatase, estrogen receptor and transforming growth factor-beta1 in Sertoli cells $[14,15]$.

Seeing microcalcifications in testicular ultrasound is not pathognomonic for LCCSCTs, but 'Christmas tree-like' calcifications of multiple lesions in syndromic LCCSCTs is almost unique for the diagnosis of this neoplasm [16]. We were able to demonstrate testicular calcifications in our patient, but we could not see Christmas tree appearance.

The aims of therapy are to decrease the polyp burden and the likelihood of polyp related complications, especially intussusception/obstruction/bleeding, in the PJS patient; and, identification of neoplasm(s) at an early stage. Endoscopic polypectomy is advised at GI endoscopy and/or colonoscopy to decrease neoplasm risks [8].

Although older reports courage orchiectomies in Sertoli cell tumors, the present management strategy is conservative including careful follow-up and ultrasound examination as these approaches avoid the long-term side effects of hypergonadotropic hypogonadism [17]. Aromatase inhibitors are the recommended pharmacotherapy for LCCSCTs $[3,7]$. We also obtained acceptable results with this approach.

\section{Conclusion}

1. Any child who was diagnosed to have invagination should have been checked for familial polyposis syndromes.

2. Any child with the suspicion of PJS should have routine mammary and testes ultrasounds. Any abnormality especially in testicles needs further evaluation including biopsy. Unexpected malignant pathologic appearance can be seen even in the youngers.

3. Malignant Sertoli cell tumors of the testes can be followed up prescribing aromatase inhibitors without any need for orchiectomy.

\section{Acknowledgments}

None.

\section{Conflict of Interest}

None declared.

\section{References}

1. Erdman SH (2007) Pediatric adenomatous polyposis syndromes: An update. Curr Gastroenterol Rep 9: 237-244.

2. Daniell J, Plazzer JP, Perera A, Macrae F (2018) An exploration of genotype-phenotype link between Peutz-Jeghers syndrome and STK11: A review. Fam Cancer 17: 421-427.

3. Armijo B, Bocklage T, Heideman R (2015) Intratubular large cell hyalinizing sertoli cell tumor of the testes in a 4-year-old male with Peutz-Jeghers syndrome. J Pediatr Hematol Oncol 37: e184-e187.

4. van Lier MG, Westerman AM, Wagner A, Looman CW, Wilson $\mathrm{JH}$, et al. (2011) High cancer risk and increased mortality in patients with Peutz-Jeghers syndrome. Gut 60: 141-147.

5. Howell L, Bader A, Mullassery D, Losty P, Auth M, et al. (2010) Sertoli Leydig cell ovarian tumour and gastric polyps as presenting features of Peutz-Jeghers syndrome. Pediatr Blood Cancer 55: 206-207.

6. Ishida H, Tajima Y, Gonda T, Kumamoto K, Ishibashi K, et al. (2016) Update on our investigation of malignant tumors associated with Peutz-Jeghers syndrome in Japan. Surg Today 46: 1231-1242.

7. Gourgari E, Saloustros E, Stratakis CA (2012) Large-cell calcifying Sertoli cell tumors of the testes in pediatrics. Curr Opin Pediatr 24: 518-522.

8. Beggs $A D$, Latchford AR, Vasen HF, Moslein G, Alonso A, et al. (2010) Peutz-Jeghers syndrome: A systematic review and recommendations for management. Gut 59: 975-986.

9. Bizzarri B, Borrelli O, de'Angelis N, Ghiselli A, Nervi G, et al. (2014) Management of duodenal-jejunal polyps in children with peutz-jeghers syndrome with single-balloon enteroscopy. J Pediatr Gastroenterol Nutr 59: 49-53.

10. Cantu JM, Rivera H, Ocampo-Campos R, Bedolla N, Cortes-Gallegos V, et al. (1980) Peutz-Jeghers syndrome with feminizing sertoli cell tumor. Cancer 46: 223-228.

11. Ulbright TM, Amin MB, Young RH (2007) Intratubular large cell hyalinizing sertoli cell neoplasia of the testis: A report of 8 cases of a distinctive lesion of the Peutz-Jeghers syndrome. Am J Surg Pathol 31: 827-835.

12. Hofmann M, Schlegel PG, Hippert F, Schmidt $P$, von-Schweinitz D, et al. (2013) Testicular sex cord stromal tumors: analysis of patients from the MAKEI study. Pediatr Blood Cancer 60: 1651-1655.

13. Brodie A, Inkster S, Yue W (2001) Aromatase expression in the human male. Mol Cell Endocrinol 178: 23-28.

14. Grandone A, del Giudice EM, Cirillo G, Santarpia M, Coppola $F$, et al. (2011) Prepubertal gynecomastia in two monozygotic twins with Peutz-Jeghers syndrome: two years' treatment with anastrozole and genetic study. Horm Res Paediatr 75: 374-379.

15. Saraco N, Berensztein E, Sciara M, de Davila MT, Ciaccio M, et al. (2006) High TGFbeta1, estrogen receptor, and aromatase gene expression in a large cell calcifying sertoli cell tumor (LCCSCT): Implications for the mechanism of oncogenesis. Pediatr Dev Pathol 9: 181-189.

16. Lefevre H, Bouvattier C, Lahlou N, Adamsbaum C, Bougneres $P$, et al. (2006) Prepubertal gynecomastia in Peutz-Jeghers syndrome: incomplete penetrance in a familial case and management with an aromatase inhibitor. Eur $\mathrm{J}$ Endocrinol 154: 221-227.

17. Goldstein SA, Hoffenberg EJ (2013) Peutz-Jegher syndrome in childhood: Need for updated recommendations? J Pediatr Gastroenterol Nutr 56: 191-195. 